\title{
A Clí́nica Pulsional de Wilhelm Reich: UMA TENTATIVA DE ATUALIZAÇÃO
}

\author{
Ricardo Amaral Rego ${ }^{1}$ \\ Instituto Brasileiro de Psicologia Biodinâmica
}

\begin{abstract}
Busca-se propor uma fundamentação da psicoterapia corporal de inspiração reichiana dentro do quadro de referência da primeira teoria freudiana das pulsões. Tenta-se explicar os elementos próprios da abordagem reichiana a partir da idéia de uma dinâmica psíquica baseada no conflito entre pulsão e defesa. Também são discutidas, brevemente, algumas possibilidades de ampliação desse modelo a partir de propostas oriundas de outras abordagens.

Descritores: Freud, Sigmund. Reich, Wilhelm. Psicanálise. Psicoterapia corporal. Pulsão.
\end{abstract}

\section{Psicoterapia corporal e Psicanálise}

耳 ste artigo examina elementos que possam incluir a psicoterapia corporal de orientação reichiana dentro de um quadro de referência psicanalítico, explorando um caminho indicado anteriormente (Rego, 1992). É uma formulação original, que se insere num movimento de diversos autores da área (Albertini, 1994; Boadella, 1997; Briganti, 1987; Silva, 2001; Wagner, 1996, 2003), no sentido de resgate das origens psicanalíticas do pensamento de Wilhelm Reich.

1 Endereço para correspondência: R. Alm. Marques Leão, 785 - 01330-010 - São

Paulo, SP. Endereço eletrônico: ric.rego@uol.com.br

Psicologia USP, 2003, 14(2), 35-59 
Em artigo anterior (Rego, 2002), mostrou-se que a psicanálise na qual Reich fundamenta suas concepções (da fase psicanalítica) é basicamente aquela da primeira teoria das pulsões (Freud, 1915/1969, 1915/1974a, $1915 / 1974 b$ ). Interessa aqui, num primeiro momento, manter este fio condutor, como se seguíssemos a pista relativa à pergunta: como teria Reich formulado suas descobertas se ele não tivesse rompido com a psicanálise?

\section{A primeira teoria freudiana das pulsões}

Cabe, inicialmente, fazer um breve resumo da teoria freudiana para, em seguida, examinarmos como Reich se apropria da mesma ao desenvolver suas propostas.

\section{Inconsciente, recalque e fixação}

A noção de inconsciente é central na metapsicologia freudiana. Este teria origem no afastamento de certos elementos psíquicos do campo da consciência, essencialmente por meio do mecanismo do recalque (Freud, 1915/1974a, 1915/1974b). Issolevaria a uma fixação, ou seja, o representante da pulsão permaneceria inalterado no inconsciente. As fixações são o elemento fundamental da psicopatologia freudiana, onde os distúrbios mentais e emocionais são sempre remontados à fixação em algum elemento passado. O tratamento ocorreria pela análise de derivados do material recalcado (os sonhos, os sintomas etc.), no sentido de "conscientizar o que é inconsc iente".

\section{A pressão (drang) da pulsão}

Para elementos não recalcados do inconsciente, o seu destino dependerá basicamente do grau de investimento libidinal: se for muito baixo, permanecerá inconsciente. Se estiver mais ativado, colocará "em movimento 
todos os processos que terminam na penetração do impulso na consciência" (Freud, 1915/1974b, p.175).

Em relação aos conteúdos recalcados, se houver um investimento suficientemente intenso da pulsão, serão rompidas todas as barreiras, e as representações associadas à pulsão chegarão à consciência. Por outro lado, um investimento fraco permitirá uma ação do recalque, e só derivados muito remotos poderão atingir o consciente. Freud afirma que "as tendências recalcadoras podem encontrar um substituto para o recalque num enfraquecimento do que é detestável" (1915/1974b, p.175).

\section{Contra-investimento e resistência}

O material recalcado exerce pressão contínua em direção à consciência, e essa força tem de ser equilibrada por uma contrapressão também incessante. Decorre daí a questão da resistência, ou seja, as mesmas forças que agem para fazer com que certos conteúdos pe rmaneçam inconscientes agirão sobre o tratamento analítico ou psicoterápico no sentido de sabotá-lo, retardá-lo ou atrapalhá-lo.

Por outro lado, essa dinâmica entre o pólo pulsional e o pólo defensivo permite compreender por que o material aparece quando as resistências são eliminadas. $\mathrm{O}$ recalcado não seria como um peixe fugidio que precisa ser pescado com grande habilidade: na verdade, de acordo com a visão freudiana, ele "quer" pular para o barco (o consciente) e não consegue porque alguma barreira o impede.

\section{O campo reichiano}

\section{A análise do caráter}

Reich (1995), no livro Análise do Caráter, fundamenta suas concepções e proposições a partir da teoria do recalque. Apesar de concordar com a 
teoria freudiana, ele propõe quatro inovações em relação à abordagem clássica da psicanálise:

a) grande importância atribuída à forma com a qual o paciente se expressa (ou seja, dar atenção não apenas ao que ele diz, mas também a como ele diz). Freud já utilizava este tipo de material, mas, em geral, não de forma prioritária. Reich colocouto como central em sua abordagem (ver Martinez, 1993).

b) a regra de associação livre de idéias seria aplicável apenas quando não há resistência importante do paciente ao desenvolvimento da análise. Quando houver resistência, o analista deve abandonar sua atitude passiva, substituindo-a por uma postura diretiva até superar as resistências ao processo. Segundo Reich (1995, p. 22), se nossos pacientes aderissem às regras fundamentais, ainda que aproximadamente, não haveria razão para se escrever um livro sobre análise do caráter. Infelizmente, só uma fração muito pequena de nossos pacientes é capaz de análise desde o princípio; a maioria deles adere às regras básicas só depois de as resistências terem sido dissolvidas com êxito.

c) o caráter, como estrutura defensiva global e articulada do ego, assume papel destacado na concepção reichiana. É enfatizado o estudo das chamadas resistências caracterológicas, que devem ser abordadas clinicamente a partir de uma técnica específica chamada análise do caráter.

d) propõe-se uma intervenção direta sobre o corpo a partir da concepção de que o conflito entre pulsão e defesa é algo que ocorre não apenas no âmbito psíquico, havendo um componente somático a considerar (ver abaixo).

\section{Reich, a Psicanálise e a musculatura}

Reich vê "a couraça 2 psíquica como a soma total de todas as forças de defesa recalcadoras" (1995, p. 289). Segundo ele, esta "couraça funciona

2 Reich usa esta denominação por acreditar que a soma das defesas psíquicas constituiria uma verdadeira blindagem ou armadura para proteger o ego. 
sob a forma de atitudes musculares crônicas e fixas." (1995, p. 313). Este é um elemento-chave de sua teoria e técnica, como se pode perceber pela afirmação de que

\begin{abstract}
a dissolução de um espasmo muscular não só libera a energia vegetativa, mas, além disso e principalmente, reproduz a lembrança da situação de infância na qual ocorreu a repressão do instinto. Pode-se dizer que toda rigidez muscular contém a história e o significado de sua origem. (Reich, 1984, p. 255).
\end{abstract}

De acordo com ele, “o que temos em mente não é uma analogia, e sim uma identidade real: a unidade da função psíquica e somática” (Reich, 1995, p. 315).

A partir de tal concepção, o trabalho direto sobre a musculatura do paciente vai se tornar parte da estratégia analítica: o afrouxamento das tensões musculares é visto como um equivalente do afrouxamento da censura e da eliminação do recalque. Inúmeros elementos, descritos por Freud em termos psíquicos, serão agora retomados somaticamente por Reich:

\title{
a) a fixação
}

Segundo Reich, "na zona oral, o recalque se manifesta pelo enrijecimento da musculatura da boca e por um espasmo na musculatura da laringe, da garganta e do peito; na zona genital, manifesta-se como tensão contínua na musculatura pélvica" (1995, pp. 316-317). Afirma ele que "a liberação da excitação vegetativa de sua fixação nas tensões da musculatura da cabeça, garganta, maxilares, laringe etc., é um dos requisitos indispensáveis para a eliminação das fixações orais em geral" (1995, p. 317). Ou seja, a fixação estaria ancorada em um padrão muscular crônico.

b) o dispêndio contínuo de energia

De acordo com Freud (1915/1974b, p. 175), "a manutenção de uma repressão ${ }^{3}$ acarreta ininterrupto dispêndio de força". Na visão reichiana, "o

3 Seguindo Laplanche e Pontalis (1991), neste artigo o termo alemão Verdrängung é traduzido como recalque. Entretanto, na passagem citada de Freud (e em outras do mesmo autor, além de algumas citações de Reich) a mesma palavra aparece traduzida comorepressão. 
encouraçamento do caráter requer energia, porque é sustentado pelo consumo contínuo de forças libidinais ou vegetativas" (Reich, 1995, p. 313). Assim, "todo aume nto de tônus muscular e enrijecimento é uma indicação de que uma excitação vegetativa, angústia ou sensação sexual foi bloqueada e ligada" (p. 315). Nesta formulação, o gasto incessante de energia, descrito por Freud como um processo psíquico, aparece para Reich como um gasto real de energia para manter o músculo contraído.

c) o recalque e a resistência

De acordo com Reich,

Observa-se, muitas vezes, que há uma diferença no estado de tensão muscular antes e depois de solucionar um recalque severo. Em geral, quando os pacientes estão em estado de resistência, isto é, quando uma idéia ou uma moção pulsional é barrada da consciência, eles sentem uma tensão no couro cabeludo, na parte superior das coxas, na musculatura das nádegas etc. Quando conseguem superar essa resistência por si mesmos ou pela interpretação correta do analista, sentem-se subitamente aliviados. (1995, p. 315)

d) a quota de afeto 4

Para Reich, "a tensão muscular que está presente e não se resolve numa descarga motora consome a excitação que poderia surgir como angústia; desse modo, evita-se a angústia." (1995, p. 319). Segundo o processo descrito por Reich, o tônus muscular aumentado consumiria justamente a excitação que, no texto freudiano, é denominada como fator quantitativo ou quota de afeto. Haveria, assim, uma correlação entre afeto e musculatura que le mbra aquilo que Freud descreveu sobre os afetos inconscientes, ou seja, enquanto as representações continuam a existir como estruturas reais no íconsciente, o que corresponde no sistema Ics. "aos afetos inconscientes é um início potencial impedido de se desenvolver.” (Freud, 1915/1974a, p. 204).

e) o recalque como um mecanismo tardio

4 Freud chama de quota de afeto à energia pulsional vinculada à idéia (Freud 1915/1974b , p. 176). 
De acordo com Freud (1915/1974b, p. 170), “a repressão não é um mecanismo defensivo que esteja presente desde o início." Ou seja, o recalque é considerado um mecanismo de defesa que não tem importância dinâmica nas primeiras fases do desenvolvimento emocional. Dentro da formulação de Reich, isso é quase óbvio, pois o recalque só poderia aparecer de forma importante por volta do fim do primeiro ano de vida, quando o desenvolvimento da coordenação motora assim o permitisse.

\section{A associação livre de movimentos}

Como decorrência das afirmações acima, a regra básica da associação livre de idéias é complementada de mane ira bastante natural por uma "associação livre de movimentos". Parece não haver traição à idéia original de Freud, quando se introduz a possibilidade de que o material inconsciente surja não apenas em termos verbais, mas também na motricidade e na expressão não-verbal do paciente.

\section{O trabalho com o pólo pulsional}

A partir da noção de um conflito entre pulsão e defesa, pode-se pensar em estratégias clínicas que trabalhem não só com o pólo defensivo (que constitui a abordagem clássica), mas que também permitam intervir no pólo pulsional. Certamente Reich não foi o único psicanalista a pensar nisso, mas provavelmente terá sido o autor que mais desenvolveu a teoria e a técnica desta forma de olhar a clínica.

Tal tipo de intervenção faria aumentar o investimento do material recalcado. Como conseqüência, produzem-se derivados em maior quantidade, mais próximos do material original e mais carregados afetivamente. Isso pode facilitar o trabalho analítico, especialmente nos casos onde a resistência está muito forte.

5 Ver nota de rodapé 2. 
Um dos recursos básicos das instâncias recalcadoras parece ser a diminuição da vitalidade geral do organismo, sendo comum verificarmos isso nos neuróticos. Um dos meios utilizados pelo organismo para tal fim - e que é da maior importância clínica - é a inibição respiratória. Muito se tem escrito sobre o papel da inibição respiratória na desvitalização do organismo e no bloqueio emocional (Gaiarsa, 1987, 1994; Keleman, 1992) e, aqui, percebemos como isso pode ser compreendido psicodinamicamente.

Fica assim clara a importância de técnicas vitalizantes e mobilizadoras utilizadas em psicoterapia corporal, como a massagem hipotônica e a massagem orgonômica (M. L. Boyesen, 2002), trabalhos sobre a respiração (Gama \& Rego, 1996; Lowen \& Lowen, 1985), o exercício da medusa ${ }^{6}$ (jellyfish), os actings desenvolvidos por Navarro (1996).

\section{O inconsciente dinâmico e a "couraça secundária"}

Como há um equilíbrio dinâmico entre pulsão e defesa, o trabalho analítico (pela ativação do material recalcado ou pela diminuição da defesa) favorece o aparecimento do material recalcado na consciência. Mas isso leva muitas vezes a uma ativação compensatória do recalque. Em outras palavras, a consequiência do fortalecimento da pulsão pode ser simplesmente uma ativação ainda maior da defesa. Conforme Freud (1926/1976) afirmou, o sinal de angústia teria como função mobilizar os mecanismos de defesa, e isto pode ter um efeito negativo para o processo analítico, se a dinâmica do conflito entre pulsão e defesa não for bem manejada pelo analista.

Esta é uma situação à qual Gerda Boyesen deu grande atenção, chamando-a couraça (ou defesa) secundária. Conforme Samson (1994), a defesa secundária se define como uma defesa recém-formada, em conseqüência de uma invasão do sistema defensivo e exposição precoce do material inconsciente reprimido. Sendo precoce, a exposição provoca uma reação de contração posterior ao primeiro suspiro de alívio, levando à formação de

Ver Heller (1993). 
uma nova defesa, mais complexa e menos aparente, que recebe o nome de secundária porque protege contra a mais recente invasora do material reprimido: a terapia (p. 44).

Isso indicaria a necessidade de uma postura mais prudente por parte do analista, no sentido de que tanto a ativação da pulsão quanto a eliminação das resistências deveriam ser feitas gradualmente, sem afobações, dentro do que é assimilável pelo paciente. Nesses casos, como diz G. Boyesen (1986), o pouco é muito (a little is a lot).

\section{Questões relativas à técnica}

Tenta-se, aqui, uma apresentação da técnica da psicoterapia corporal que se assente na metapsicologia freudiana, e não, como é usual, nos pressupostos biológicos e energéticos da formulação reichiana tradicional.

\section{A Psicologia Biodinâmica de Gerda Boyesen}

Foi visto acima que, partindo de uma base teórica bastante semelhante, a técnica psicanalítica e a técnica reichiana clássica tomaram rumos distintos, chegando mesmo ao antagonismo em muitos aspectos. Na Psicologia Biodinâmica (G. Boyesen, 1986; Iaconelli, 1997), existem elementos que talvez permitam uma síntese entre estas abordagens, integrando-as num contexto mais amplo.

Recupera-se, por exemplo, a valorização da passividade do analista, que permite que o terapeuta atue dando espaço para um processo espontâneo que brote do paciente. De acordo com G. Boyesen (1986),

As senhas durante a vegetoterapia são as seguintes: digo ao paciente: Você pode dizer ou fazer o que quiser. Mas você não é obrigado a fazer ou dizer, seja lá o que for. Simplesmente, não contenha nenhuma palavra ou movimento. Diga se existe alguma coisa que você queira que eu diga ou que eu faça (...) chamo este método terapêutico de método da parteira. (p. 102). Aí está realmente o segredo da terapia 
biodinâmica: deixar o processo biodinâmico emergir das profundezas do corpo; as emoções surgem por si e se descarregam. (p. 105).

Entretanto, quando existe resistência, a postura proposta é semelhante à de Reich (ver item 3.1, item b): "fiz uma distinção entre os pacientes que já tinham em si um processo dinâmico e aqueles que precisavam de uma intervenção de minha parte." (G. Boyesen, 1986, p. 104).

Este tipo de concepção talvez possa constituir um eixo em torno do qual seria possível estruturar uma técnica que integre aspectos das várias escolas psicanalíticas e das diversas abordagens reichianas e neo-reichianas numa proposta abrangente e, ao mesmo tempo, coerente.

\section{O paradigma pulsional e a análise da resistência}

Os aspectos abordados a seguir configuram uma visão da clínica estruturada com base na noção de resistência, procurando articular o manejo dos vários graus e das diversas formas de ocorrência da mesma.

Outros elementos fundamentais de um processo analítico deveriam ser examinados para que se constituísse uma proposta mais completa, mas não serão aqui abordados por estarem fora do âmbito deste artigo. Entre estes, merece atenção especial a questão da transferência, dado que as alterações propostas em relação ao setting analítico tradicional acarretam uma profunda modificação dos aspectos transferenciais do tratamento. Note-se que existem autores do campo reichiano que têm estudado o fenômeno da transferência no contexto da psicoterapia corporal, como Wagner (2003) e Samson (2002).

Examinemos, então, a questão da resistência. Ela varia (em quantidade e qualidade) de pessoa para pessoa. Ela varia, ainda, ao longo do tempo para um mesmo paciente, ocasionando fases do tratamento com maior ou menor resistência, podendo inclusive ser diferente em momentos diversos de uma mesma sessão. Assim, propõe-se uma postura geral que deverá levar em conta, para sua aplic ação, a leitura atenta da especificidade de cada pessoa e de cada momento do processo analítico. É o que se pode chamar de 
postura do alfaiate: em vez de usar a mesma roupa pronta para todos, buscase criar uma que se adapte às medidas específicas daquele que está sendo atendido.

Considerando a quantidade de resistência, propõe-se, aqui, que este tema seja visto como um continuum onde podem ocorrer infinitos graus de variação entre dois pólos: de um lado, a resistência absoluta e impenetrável; de outro, a ausência completa dela. Quanto menor a resistência, mais os conteúdos recalcados inconscientes podem aflorar sem distorções, até mesmo sem necessidade de interpretações. Desta maneira, quando a resistência é mínima, cabe ao analista apenas cuidar de não atrapalhar o processo.

Pela mesma lógica, quanto maior a resistência encontrada, maior será o papel diretivo do analista. Isto também parece óbvio, e é um dos pontos enfatizados brilhantemente por Reich ${ }^{7}$ : se há uma forte resistência, não levará a lugar algum a postura de abrir espaço para as associações livres (verbais ou motoras) do paciente, pois ele simplesmente andará em círculos, cerceado pelos seus próprios mecanismos de defesa. Graus intermediários de resistência exigirão uma atitude mista do analista, obviamente. Ou seja, o comando do tratamento é atribuído ao paciente ou ao analista, conforme a quantidade de resistência, e esta pode variar a cada momento do processo: é muito freqüente que a um momento de fluidez siga-se, subitamente, na mesma sessão, um período de resistência. Ou o contrário: depois de um início frio e resistente, abre-se a comunicação.

Além da quantidade de resistência, seria importante a atenção à qualidade da mesma. Além da resistência comum descrita por Freud, Reich introduz o estudo da resistência que está ligada ao caráter. A proposta dele é que esta forma de resistência, por suas características especiais ${ }^{8}$, só pode ser

7 "No período de resistência, recai sobre o analista a difícil tarefa de dirigir o andamento da análise. O paciente só tem comando nas fases livres de resistência" (Reich, 1995, p. 49).

8 O traço de caráter, normalmente, estaria estruturado na personalidade, não sendo visto como algo estranho à pessoa; seria crônico; muitas vezes apareceria somente na forma e não no conteúdo das comunicações do paciente; ocorreria ainda, freqüentemente, como uma resistência oculta ou latente. 
eliminada quando se usa uma técnica específica, denominada de análise do caráter (Reich, 1995).

Outra forma de resistência diferente da descrita por Freud seria aquela constituída a partir de aspectos somáticos. Desta forma, abre-se a possibilidade de uma ação para eliminar a defesa a partir de um trabalho direto sobre o corpo do paciente. Por exemplo, afrouxando a tensão muscular (e as defesas contra o recalcado) por meio de massagens (ver G. Boyesen, 1986, pp. 34-41) ou de exercícios de sobrecarga da musculatura (Lowen, 1985). Reich enfatizou a questão da hipertonia muscular no seu estudo dos aspectos somáticos da defesa psíquica. Outros autores acrescentaram novos elementos à sua concepção: o papel defensivo da hipotonia muscular, das "couraças" tissular e visceral (G. Boyesen, 1986).

O emprego da leitura corporal, ou seja, a valorização dos elementos de comunicação não-verbal que se manifestam na relação analítica, pode ser considerado um outro elemento decisivo. Supõe-se, aqui, que os derivados do material recalcado aparecem não só no discurso, mas também na ação. A forma, portanto, seria tão reveladora quanto o conteúdo das comunicações do paciente. Assim, neste tipo de abordagem, o "olhar analítico" adquire a mesma importância da "escuta analítica". Ele pode ser decisivo para a identificação tanto de aspectos crônicos (como um traço de caráter), quanto em relação a resistências só detectáveis por certo brilho no olhar ou uma mudança sutil na postura.

Até aqui a abordagem da resistência ocorreu, basicamente, por meio de uma abordagem do pólo defensivo do conflito entre pulsão e defesa. Um outro princípio seria a possibilidade de trabalho com o pólo pulsional. Como foi visto anteriormente (item 2), Freud afirmou que um "enfraquecimento do que é detestável" poderia substituir o recalque, pois a retirada do investimento de um representante da pulsão faria com que este não pressionasse, ou pressionasse menos, em direção à consciência e à ação. Inúmeros exe mplos de técnicas deste tipo são encontrados nas abordagens reichianas e neoreichianas (ver item 3.4). 
Coerentemente com as considerações anteriores, o setting deve ser flexível. Isso significa, por exemplo, que a distância entre paciente e analista pode variar conforme o caso - algumas pessoas necessitarão de pouca distância, para que o calor humano do contato próximo "derreta as resistências". Outras, entretanto, acharão essa mesma proximidade invasiva, e suas resistências diminuirão quando a angústia trazida por essa ameaça atenua-se por meio de um afastamento físico entre os participantes da sessão ${ }^{9}$. Além disso, o psicoterapeuta não precisa ficar "aparafusado" na caceira durante uma mesma sessão: ele pode circular ${ }^{10}$, ficando mais próximo ou distante, conforme o decorrer dos acontecimentos, podendo, assim, mudar o ângulo de interação.

Em certas fases do processo de alguns pacientes é muito útil o setting analítico tradicional. A posição relaxada e a falta de contato visual induzem a um contexto propício ao contato do paciente consigo mesmo, ao mesmo tempo em que a ausência de contato físico lhe assegura que não será invadido. O material pode aparecer sob a forma clássica de relatos verbais, mas há, também, a liberdade para que isso aconteça por meio da associação livre de movimentos, podendo ocorrer mudanças de postura, gestos, sons e movimentos expressivos.

9 Obviamente, a proximidade entre pessoas não se mede apenas em metros, podendo a distância afetiva ser modulada por meio do tom de voz, entre outras possibilidades. Entretanto, o manejo apropriado da distância física permite uma intervenção mais precisa: pode-se determinar o grau ótimo de proximidade para um dado paciente e investigar como ele vivencia, em seu corpo e em seus afetos, quando nos afastamos (ir embora abandono) ou nos aproximamos (invasão, sedução).

10 G. Boyesen (1986, p. 102) relata: "eu podia me sentar longe do paciente, a seu lado, atrás, na frente, muito perto e mesmo podia tocá-lo."

11 Estar à frente pode ter uma conotação de enfrentar, mas também pode constituir um contato mais direto e com exposição mútua. Estar ao lado tem um significado óbvio, e pode ser uma posição de escolha em certos momentos do processo. Um ângulo de $90^{\circ}$ pode caracterizar um ambiente de interação menos exposto e mais protegido, adequado para condições que requeiram um contato no qual é importante que não se caracterize um clima de enfrentamento. 
Para alguns, entretanto, a falta de contato visual gera angústia, pode ndo chegar ao ponto de inibir a comunicação. O mesmo acontece com a postura deitada que, em alguns momentos, pode ser sentida pelo paciente como algo ameaçador que vai precipitá-lo num abismo desconhecido. Em certos casos, interpreta-se a resistência e permanece o enquadre original. Em outros, o tratamento pode fluir melhor ao optar-se pela inserção do contato visual e/ou da postura sentada. Sempre partindo de uma leitura psicodinâmica do que está acontecendo com aquela pessoa, naquele momento e dentro de qual vivência transferencial específica.

Com pacientes para os quais o contato físico não é problema, pode-se usar uma variação da posição analítica tradicional, acrescentando a ela o toque: o psicoterapeuta coloca suas mãos sob a cabeça do paciente, apoiando-a, enquanto seus dedos trabalham sobre a nuca e parte posterior do pescoço. $\mathrm{O}$ afrouxamento da resistência ancorada nas tensões em sua nuca e pescoço contribui, muitas vezes, para o surgimento mais fácil do material recalcado. O medo de "perder a cabeça" é comum quando nos aproximamos do contato com o desconhecido que somos para nós mesmos, e a tentativa de controle, freqüentemente, está ancorada em tensões desse tipo. Uma vantagem adicional dessa posição é que muitas pessoas referem uma sensação de conforto e confiança pelo fato de terem a cabeça apoiada. $\mathrm{O}$ aspecto relacional tem, então, um efeito sinérgico com o trabalho somático, facilitando o derretimento das resistências. Como já afirmado, outras pessoas perceberão esse contato como algo inva sivo que motivará um sentimento de repulsa. Cada caso é um caso.

Obviamente, estas possibilidades não são as únicas, podendo uma sessão ocorrer com os participantes em pé, sentados, em movimento ou em qualquer posição que se perceba ser efetiva para os objetivos.

De um modo geral, existe a necessidade de estruturar o setting, a abordagem, a técnica e o manejo da relação no sentido de ter como resultado a diminuição ou eliminação da resistência. Como cada pessoa é diferente, a estratégia também será diversa em cada caso. Para alguns, o importante é sentir-se acolhido e protegido. Isso fará com que as defesas baixem a guarda 
e deixem vir à tona o que estava guardado. Para outros, talvez porque tenham sido muito manipulados na infância, isto terá efeito contrário. Certa vez, uma paciente pediu-me indicação de um psicoterapeuta para seu namorado. Assim o fiz e, algum tempo depois, ela relatou que o rapaz não havia gostado da psicoterapeuta indicada, pois lhe parecera "boazinha" demais. Ou seja, ele não precisava de alguém que fosse acolhedor e atencioso, mas de um psicoterapeuta mais franco e direto, que apontasse seus conflitos sem muitos rodeios, sem "sedução". A questão da confiança no analista pode ser um fator decisivo no afrouxamento das resistências. Uma pessoa submetida a tratamento biodinâmico nos conta, por exemplo: "eu sabia que, se eu mergulhasse dentro de alguma coisa, que o massagista ia ficar comigo, que ele não ia escapar e ir por outro caminho (...) a prioridade dele era me acompanhar." (Iaconeli, 1997, p. 55).

Um último princípio consiste na postura biodinâmica de fazer amizade com a resistência (G. Boyesen, 1986). Este princípio tem como base, por um lado, não ceder à resistência e não compactuar com ela. Por outro, não tentar removê-la de uma forma que exceda a capacidade de assimilação do paciente. Em uma analogia que pode ser útil, a resistência seria como uma muleta que permite à pessoa andar e que, em uma dada situação infantil, foi provavelmente a melhor solução possível, dentro dos recursos então existentes. Se tentarmos chutar essa muleta para longe, o paciente reagirá, aga rrando-se a ela para não cair. Mas se lhe oferecermos um programa viável de tratamento que recupere as capacidades perdidas, ele provavelmente aderirá e logo abandonará por si mesmo a muleta.

\section{Para além do paradigma pulsional}

Até aqui, seguimos o fio condutor do paradigma pulsional. Entretanto, o exame do campo da psicoterapia corporal atual aponta elementos que parecem não caber dentro desta fundamentação. Dentro dos propó sitos deste artigo, não cabe o exame aprofundado deste tema. Entretanto, o assunto fica- 
ria um tanto incompleto se não fossem indicadas algumas direções em que se pode ampliar a base conceitual e técnica.

\section{Outras Psicanálises}

Em primeiro lugar, é necessário examinar a produção freudiana não incorporada por Reich. Como foi dito, a teoria reichiana articula-se bem com a primeira teoria das pulsões de Freud. Mas isso não quer dizer que ela esteja correta. Um primeiro questionamento seria: por que não seguir a segunda teoria freudiana, que fala da pulsão de morte? Afinal de contas, o próprio Freud deixou de lado sua primeira formulação em favor da segunda. Este é um tema amplo, e alguns aspectos dessa discussão foram elaborados em trabalho anterior (Rego, 2001 ), no qual se procura mostrar que pode não ser inapropriado preferir a primeira teoria das pulsões.

Quanto à psicanálise depois de Freud, fica difícil posicionar-se, tamanha a diversidade de escolas e formulações dentro do campo psicanalítico. Segundo Bleichmar e Bleichmar (1992, p. 17),

a teoria psicanalítica cresceu, a partir de Freud, por aposição de uma grande quantidade de escolas, correntes de pensamento, grupos, autores, cada um com seu enfoque particular sobre quase todos os problemas. Poderíamos dizer que, neste momento, não há uma psicanálise, mas muitas.

Utilizaremos, aqui, a proposição de Mezan (1996), de agrupar as diferentes abordagens psicanalíticas em três grandes paradigmas: o paradigma pulsional (Freud, Abraham, Reich), o paradigma relacional ou objetal (Fairbairn, Winnicott, Sullivan) e o paradigma do sujeito (Lacan).

De acordo com este autor, "foi a chegada aos consultórios de pacientes deprimidos, psicóticos, fronteiriços, portadores de distúrbios de caráter ou de falhas profundas na organização do narcisismo que deu origem ao questionamento do paradigma pulsional" (Mezan, 1996, p. 353). Como resposta a isso, organiza -se, a partir dos anos 50, outra forma de compreender o inconsciente, que recusa a centralidade do conceito de pulsão. Trata-se de uma perspectiva na qual a experiência humana não é primordialmente mol- 
dada pelo interjogo das pulsões, mas pela maneira como se organizam as primeiras relações do bebê com os outros seres humanos. Nessa linha, vários autores “(...) buscam conceitualizar a importância central que atribuem ao objeto e às relações como constituintes últimos do inconsciente” (pp. 350$351)$.

Ainda segundo Mezan, a frase "a libido não busca prazer, busca objetos", de Fairbairn, "se converte na senha de todos os autores desta tendência." (1996, pp. 350-351). O que se vê hoje é que o campo reichiano, sem negar sua fundamentação pulsional, tem dialogado com autores da escola de relações objetais como forma de ampliar os horizontes clínicos. Entre estes, especialmente as idéias de Donald Winnicott têm motivado interesse, como se pode ver, por exemplo, em Cintra (2002) e Cornell (1998).

Quanto ao diálogo com o paradigma lacaniano, este é um campo em aberto, e poucas explorações desse território existem. Entre elas, pode-se citar aquela feita por Cukiert (2000), que parece apontar, a meu ver, mais para uma complementaridade do que para um antagonismo entre as visões de Reich e Lacan.

\section{Outros inconscientes}

De acordo com Freud (1915/1974b, p. 191), "tudo que é reprimido deve permanecer inconsciente; mas, logo de início declaremos que o reprimido não abrange tudo que é inconsciente. $\mathrm{O}$ alcance do inconsciente é mais amplo: o reprimido é apenas uma parte do inconsciente." Em "O Ego e o Id", essa tese é confirmada quando se diz que "o reprimido se funde com o id, e é simplesmente uma parte dele” (Freud, 1923, p. 38).

Muitos elementos do funcionamento mental e do tratamento de distúrbios psíquicos podem não ser explicáveis pela teoria do recalque. Mas, talvez, seja útil pensá-los no âmbito mais amplo de processos inconscientes que podem ser trazidos à consciência em um dado processo terapêutico. Isso não é novidade, constituindo uma idéia abordada de diferentes maneiras por diversos autores. 
Klein (1991), por exemplo, enfatiza a importância dos processos mentais que ocorrem no primeiro ano de vida, numa época da vida em que o mecanismo do recalque ou está ausente ou ainda não tem a importância que terá posteriormente. $\mathrm{O}$ inconsciente é entendido como algo também relacionado a mecanismos de defesa mais primitivos, como a negação, a cisão, a projeção e a introjeção. Isso amplia e modifica a visão freudiana descrita acima.

Alguns autores propõem a hipótese da existência de um inconsciente filogenético, que faria parte do psiquismo humano e que teria uma similaridade com o que Jung chamou de inconsciente coletivo. Stevens e Price (1996), por exemplo, propõem um modo de conceber a Psiquiatria a partir da hipótese, proposta por C. G. Jung, do funcionamento dos arquétipos como unidades dinâmicas do psiquismo filogenético:

... arquétipos são concebidos como unidades neuropsíquicas que evoluíram através da seleção natural e que são responsáveis pela determinação de características comportamentais e também de experiências afetivas e cognitivas típicas dos seres humanos (...) por exemplo, o sistema arquetípico mãe-bebê apenas será plenamente preenchido se for ativado pela presença e pelo comportamento de uma figura materna (pp. 6-7).

Não cabe, aqui, discutir a validade ou não deste tipo de concepção. Interessa-nos, apenas, citar exemplos que falam da possibilidade da existência de outros tipos de inconsciente que influenciam a vida mental, e para os quais continuaria existindo um efeito terapêutico na atividade de "conscientizar o que é inconsciente". Do mesmo modo, em psicoterapia corporal, muitas vezes deparamo-nos com fenômenos que sugerem a existência de um outro tipo de inconsciente (aqui chamado de neurolocomotor), que parece ser formado sem a ação do recalque.

É o que acontece quando se aprende a andar, por exemplo. O aprendizado depende, em geral, de uma atenção consciente, que permite um desenvolvimento e aprimoramento do movimento e da capacidade de ação. Gradualmente, a coordenação vai se automatizando e ficando inconsciente, até um ponto em que é necessário um grande esforço para conscientizar nova- 
mente os procedimentos que constituem a ação como, por exemplo, alguém que quer corrigir uma postura errada ao tocar um instrumento.

Desta maneira, existiria um processo inconsciente de comando da motricidade. Entretanto, a dinâmica, aqui, pode ser inteiramente diferente daquela que ocorre no recalque:

a) não haveria uma força impelindo naturalmente o conteúdo inconsciente em direção à consciência;

b) não existiria, portanto, uma pressão pelo "retorno" do material inconsciente, e este não estaria presente em atos falhos, sonhos e sintomas;

c) o que está inconsciente não seria uma pulsão ou um representante da pulsão, isto fazendo com que o papel da sexualidade não seja necessariamente o principal, como ocorre no caso do inconsciente recalcado;

d) este seria simplesmente um mecanismo neurológico normal, e não um processo patológico;

e) não parece haver uma representação recalcada que é afastada da consciência;

f) existiriam procedimentos que podem tornar-se inconscientes em qualquer fase da vida, não havendo assim, necessariamente, uma predominância dos elementos infantis;

g) o papel da angústia parece ser diferente neste caso, tanto no processo de tornar inconsciente um material consciente, como no processo inverso.

Entretanto, algumas similaridades podem ser notadas entre este processo de automatização e o recalque. Uma é a questão dos afetos, pois quando um procedimento motor é automatizado, ele pode incorporar em si algo da dinâmica emocional do momento em que este procedimento foi gerado. Por exemplo, uma criança aprende a andar num momento em que vive intenso ódio pela chegada de um irmão. Ao ser automatizada sua maneira de 
andar, nessa época da sua vida, ela possivelmente incorporará em seu modo um jeito de andar "pisando duro "12, que poderá permanecer, assim, pelo resto de sua existência. Ou seja, haveria aqui também uma "fixação" infantil, cuja dinâmica, entretanto, pode ser bem diversa daquela originada pelo recalque. É de se supor que a intervenção terapêutica também apresente características diferentes daquelas descritas acima.

Outra semelhança seria a resistência à mudança. Parece haver uma tendência de preservação dos comportamentos aprendidos, o que é compreensível neurologicamente: seria um contra-senso, em termos do or ganismo, desorganizar um comportamento que "funciona", é preciso conservar aquilo que foi organizado e tornou-se um padrão viável. Porém, aparentemente, não há uma psicodinâmica envolvida nesta resistência. Se a hipótese aqui analisada for verdadeira, o modo de lidar com esta resistência terá de ser diferente daquele discutido anteriormente.

A metodologia proposta por Keleman $(1992,1995)$ parece estar voltada para este tipo de questão e, talvez, não seja à toa que ele não utiliza o referencial teórico e técnico da psicanálise ou da tradição reichiana. É um trabalho voltado para a reorganização de padrões musculares e emocionais, no qual a ampliação da propriocepção e do controle sobre a motricidade adquirem papel preponderante. Não há algo que se deixa vir à tona, pois o ego vai buscar ativamente aumentar seu controle, numa mudança escolhida e dirigida para uma direção determinada.

\section{Conclusões}

Em primeiro lugar, parece ser possível descrever a clínica da psicoterapia corporal, tendo como base a teoria freudiana das pulsões. Isto confir-

12 Decorrente dos fortes sentimentos de ódio e insegurança que estiveram muito presentes na época do aprendizado motor. Talvez, expressando até um desejo de pisar no irmão. 
maria a hipótese de que o paradigma pulsional foi o eixo teórico, a partir do qual Reich derivou suas abordagens técnicas inovadoras.

Em termos de um diálogo com a psicanálise, este posicionamento permitiria localizar a psicoterapia corporal dentro de um tipo de abordagem psicanalítica específica, possibilitando que ela se enriqueça no contato com a vasta literatura que aborda temas teóricos e clínicos neste campo.

Quanto ao desenvolvimento das possibilidades aqui apontadas, parece ficar claro que o paradigma pulsional freudiano não dá conta de todas as possibilidades e propostas da psicoterapia corporal contemporânea. Talvez se possa dizer que o conflito entre pulsão e defesa é um modelo necessário, mas não suficiente, para compreender a clínica reichiana atual. Podem e devem ser buscados novos elementos em autores psicanalíticos que trouxeram inovações e perspectivas diferentes da tradicional, para que se complete este quadro. Citam-se, aqui, especialmente, as idéias de Donald Winnicott como promissoras neste aspecto.

A grande inovação reichiana é a idéia da participação dos aparelhos locomotor e respiratório na dinâmica psíquica. Este é um tema que merece ser aprofundado e debatido, tanto no sentido de um desenvolvimento da metodologia clínica, quanto em relação ao seu embasamento científico no âmbito da biologia e das neurociências. Note-se que esta hipótese reichiana não é essencialmente diferente da abordagem psicanalítica tradicional. Ao descrever a importância das zonas erógenas oral, anal e genital, em "Três Ensaios sobre a Teoria da Sexualidade", Freud (1905/1972, p. 188) ressalta que

qualquer outra parte do corpo pode adquirir a mesma suscetibilidade ao estímulo possuída pelos órgãos genitais e pode tornar-se uma zona erógena (...) fui levado a atribuir a qualidade de erogeneidade a todas as partes do corpo e a todos os órgãos internos.

Desta maneira, Reich nada mais faz do que investigar uma possibilidade já assinalada por Freud, ampliando os horizontes do corpo erógeno ao explorar as possibilidades de se entender e trabalhar clinicamente com a importância psíquica dos aparelhos respiratório e locomotor. Talvez se possa 
caminhar ainda mais nesta direção, incorporando, por exemplo, a pele (Anzieu, 2000; G. Boyesen, 1986) e outros órgãos e sistemas do organismo a uma visão mais abrangente do funcionamento psíquico.

Rego, R. A. (2003). Wilhelm Reich's drive practice: an attempt of updating. Psicologia USP, 14(2), 35-59.

Abstract: The aim of this article is to understand the Reichian body psychotherapy within the framework of the first Freudian drive theory. We try to explain specific elements of the Reichian approach starting from the idea of a psychodynamic based on the conflict between drive and defense. Some possibilities of expanding this model through the integration of proposals from other theories are also briefly discussed.

Index terms: Freud, Sigmund. Reich, Wilhelm. Psychoanalysis. Bodypsychotherapy. Drive.

Rego, R. A. (2003). La clinique pulsionnelle de Wilhelm Reich : une tentative d'actualisation. Psicologia USP, 14(2), 35-59.

Résumé: On propose une base de psychothérapie corporelle d'inspiration reichienne dans le cadre de référence de la première théorie freudienne des pulsions. On cherche à expliquer les éléments propres à l'abordage reichinien à partir de l'idée d'une dynamique psychique basée sur le conflit entre pulsion et défense. On discute aussi, brièvement, des possibilités d'extension de ce modèle à partir des propositions venant d'autres façons de voir.

Mots clés: Freud, Sigmund. Reich, Wilhelm. Psychanalyse, Psychothérapie corporelle. Pulsion. 


\section{A Clínica Pulsional de Wilhelm Reich: Uma Tentativa de Atualização}

\section{Referências}

Albertini, P. (1994). Reich: História das idéias e formulações para a educação. São Paulo: Ágora.

Anzieu, D. (2000). O Eu-pele (2a ed.). São Paulo: Casa do Psicólogo.

Bleichmar, N. M., \& Bleichmar, C. L. (1992). A psicanálise depois de Freud: Teoria e clínica. Porto Alegre, RS: Artes Médicas.

Boadella, D. (1997). Psicoterapia somática: Suas raízes e tradições. Uma perspectiva pessoal. In R. Kignel (Org.), Energia e caráter 1 (pp. 13-42). São Paulo: Summus.

Boyesen, G. (1986). Entre psiquê e soma. São Paulo: Summus.

Boyesen, M. L. (2002). Massagem orgonômica. In R. A. Rego \& A. Samson (Orgs.), Massagem biodinâmica. São Paulo. Publicado eletronicamente em www.ibpb.com.br

Briganti, C. (1987). Corpo virtual. Reflexões sobre a clínica psicoterápica. São Paulo: Summus.

Cintra, M. G. P. (2002). Gerda Boyesen, a mãe suficientemente boa descrita por Winnicott. Revista Reichiana, (11), 38-62.

Cornell, W. F. (1998). Se Reich tivesse encontrado Winnicott: O gesto interrompido. Revista Reichiana, (7), 80-97.

Cukiert, M. (2000). Uma contribuição à questão do corpo em Psicanálise: Freud, Reich e Lacan. Dissertação de mestrado, Inst ituto de Psicologia, Universidade de São Paulo, São Paulo.

Freud, S. (1969). Os instintos e suas vicissitudes. In S. Freud, Edição standard brasileira das obras psicológicas completas de Sigmund Freud(Vol. 14, pp. 129162). Rio de Janeiro: Imago. (Trabalho original publicado em 1915)

Freud, S. (1972). Três ensaios sobre a teoria da sexualidade. In S. Freud, Edição standard brasileira das obras psicológicas completas de Sigmund Freud (Vol. 7, pp. 123-250). Rio de Janeiro: Imago. (Trabalho original publicado em 1905)

Freud, S. (1974a). O inconsciente. In S. Freud, Edição standard brasileira das obras psicológicas completas de Sigmund Freud(Vol. 14, pp. 185-251). Rio de Janeiro: Imago. (Trabalho original publicado em 1915)

Freud, S. (1974b). Repressão. In S. Freud, Edição standard brasileira das obras psicológicas completas de Sigmund Freud(Vol. 14, pp. 169-182). Rio de Janeiro: Imago. (Trabalho original publicado em 1915) 


\section{Ricardo Amaral Rego}

Freud, S. (1976). O Ego e o Id In S. Freud, Edição standard brasileira das obras psicológicas completas de Sigmund Freud (Vol. 19, pp. 13-83). Rio de Janeiro: Imago. (Trabalho original publicado em 1923)

Freud, S. (1976). Inibições, sintomas e ansiedade. In S. Freud, Edição standard brasileira das obras psicológicas completas de Sigmund Freud (Vol. 20, pp. 95201). Rio de Janeiro: Imago. (Trabalho original publicado em 1926)

Gaiarsa, J. A. (1994). Respiração, angústia e renascimento (2. ed.). São Paulo: Ícone.

Gaiarsa, J. A. (1987). Respiração e circulação. São Paulo: Brasiliense.

Gama, M. E. R., \& Rego, R. A. (1996). Grupos de movimento. In Cadernos Reichianos 1 (2a ed.). São Paulo: Instituto Sedes Sapientiae.

Heller, M. (1993). The Jellyfish, or the Reichian world of Gerda Boyesen. Energy and Character, 24(2), 1-27. (Tradução para o português da parte II publicada eletronicamente em www.ibpb.com.br, 2002)

Iaconelli, V. (1997). Psicologia biodinâmica: Reflexão de uma prática organizando-se em teoria. Dissertação de mestrado, Instituto de Psicologia, Universidade de São Paulo, São Paulo.

Keleman, S. (1992). Padrões de distresse. São Paulo: Summus.

Keleman, S. (1995). Corporificando a experiência. São Paulo: Summus.

Klein, M. (1991). Notas sobre alguns mecanismos esquizóides. In M. Klein, Inveja e gratidão e outros trabalhos (pp. 17-43). Rio de Janeiro: Imago.

Laplanche, J., \& Pontalis, J. B. (1991). Vocabulário da psicanálise (11a ed.). São Paulo: Martins Fontes.

Lowen, A., \& Lowen, L. (1985). Exercícios de bioenergética. São Paulo: Ágora.

Martinez, C. B. (1993). O universo visual no trabalho clínico da psicanálise de Freud, Ferenczi e Reich. Encontro: Revista do Departamento de Psicologia do I. E. S. Senador Flaquer, (3), 17-26.

Mezan, R. (1996). Paradigmas e modelos na psicanálise atual. In N. M. Pellanda \& L. E. C. Pellanda (Orgs.), Psicanálise hoje: Uma revolução do olhar (pp. 347-355). Petrópolis, RJ: Vozes.

Navarro, F. (1996). Metodologia da vegetoterapia caractero-analítica. São Paulo: Summus.

Rego, R. A. (1992). Apontamentos para uma abordagem integrada em psicoterapia reichiana. Revista Reichiana (1), 100-117.

Rego, R. A. (2001). Temas utópicos e outros tópicos. São Paulo. Publicação eletrônica disponível em www.ibpb.com.br 


\section{A Clínica Pulsional de Wilhelm Reich: Uma Tentativa de Atualização}

Rego, R. A. (2002). Reich e Freud: Co mpatibilidades e incompatibilidades. Revista da Sociedade Wilhelm Reich, 5(5), 59-74.

Reich, W. (1984). A função do orgasmo (10a ed.). São Paulo: Brasiliense.

Reich, W. (1995). Análise do caráter (2a ed.). São Paulo: Martins Fontes.

Samson, A. (1994). A couraça secundária. Revista Reichiana, (3), 44-51.

Samson, A. (2002). Transferência e contratransferência em psicoterapia corporal. São Paulo. Publicação eletrônica disponível em www.ibpb.com.br

Silva, J. R. O. (2001). O desenvolvimento da noção de caráter no pensamento de Reich. Dissertação de mestrado, Instituto de Psicologia, Universidade de São Paulo, São Paulo.

Stevens, A., \& Price, J. (1996). Evolutionary psychiatry. A new beginning. London: Routledge.

Wagner, C. M. (1996). Freud e Reich: Continuidade ou ruptura? São Paulo: Summus.

Wagner, C. M. (2003). A transferência na Clínica Reichiana. São Paulo: Casa do Psicólogo.

Recebido em 05.06.2003

Aceito em 17.09.2003 